\title{
Statistical Analysis of Larval and Pit Size of Antlion (Family: Myrmeleontidae) with Short Notes on its Trailing Behaviour
}

\author{
Anila Krishnan ${ }^{1}$, Francy Kunhip Kakkassery ${ }^{2}$ \\ ${ }^{1,2}$ Research \& Postgraduate, Department of Zoology, St. Thomas' College (Autonomous), Thrissur, Kerala, India
}

\begin{abstract}
Antlion larvae makes pits in the sandy soil with their mandibles. The natural predators on ants, they have a special strategy to predate. Pit building in loose sandy soil is the fascinating behaviour pattern shown by antlion larvae. The relationship between the antlion larval size and pit size were analysed using standard software. A total of sixty pits were analysed for this study and the measurements were made. Twelve of them are non resident pits. From correlation analysis, a high positive correlation between larval body width and pit diameter and a negative correlation between larval head length and pit depth were found. Also instar determination was done by using highly correlated parameters. From this result, we can predict the larval size of antlions inhabiting a pit by using its pit diameter. Approximately the diameter of pit 1.2-2.2, 2.2-3.2, 3.2-4.2 have the larvae with body size 2.9, 3.4, 3.8 respectively. A short note regarding the trailing behaviour of larvae is also included. The trailing was started within 3sec to 50 minutes from the introduction of larvae to the soil and started from the centre to the north of the tray in every experiment.
\end{abstract}

Keywords: Antlion larval size, pit size, instar determination, trailing behaviour.

\section{Introduction}

Myrmeleontids, consisting of nerve - winged creatures commonly known as antlions, are the least studied insect group in India. They belong to Family Myrmeleontidae, Order Neuroptera with membraneous wings which are held roof like while resting. The life cycle includes a larval stage which is fascinating with so many behaviour patterns such as pit building, predatory and trailing. Antlion larva are sedentary predators, which dig in sandy soils and capture its preys, mostly ants.

The antlion larva has three instars in its life cycle. In each instar the size will increase progressively and it will stop prior to pupation. With the help of body size and pit characteristics we can determine the instar of pit dwelling larvae. Mainly head width is used as an indicator of body size (Arnett et al. 1999), from which we can decide the instar of antlion larvae. But here we are going to predict the stage of larvae in a pit with highly related parameter of pit. The pit characteristics are very significant in the case of antlion larvae hence it is a natural predator. Larva use their pit to capture insects mostly ants in the natural habitat. The diameter, depth etc of the pit is highly significant for the capture success of prey and also pit diameter was significantly correlated with larval size (Prado et al. 1993). But studies have revealed that there is a relationship between larval size and diameter of the pit (Simberloff et al. 1978, Griffiths 1980, Heinrich and Heinrich 1984).

There are studies regarding the change in Pit diameter and larval mass in different seasons. Pit diameter varied 7 fold and the larval mass varied 60 fold in early spring (Heinrich and Margaret 1984). Not only season causes the change in pit size but also the past pit- building experience and food limitation influence the pit size changes (Liang et al. 2010). Within each larval instar (Myrmeleon pictifrons) there is a linear, increasing relationship between larval size and pit size (Kitching 1984). Larval and adult body size increased with latitude, but decreased with elevation (Arnett et al. 1999)

\section{Methodology}

The study was conducted in the sunshade of an abandoned house in a village called Parli in Palakkad district, the central northern district of Kerala State bordering Tamilnadu, and the study was conducted from April 1 - May 30,2015 . A good number of pits were there but due to unexpected summer rain the antlion pits spread outside the sunshade were damaged. The remaining pits were studied for the correlation purpose. The depth and diameter were noted without disturbing the antlion larvae. Pit diameters and depth were measured to the nearest $\mathrm{mm}$. The soil temperature of the study area was between $37^{\circ} \mathrm{C}-41^{\circ} \mathrm{C}$.

The following parameters were studied for the correlation purpose such as, Pit depth, Pit diameter, Larval head length, Larval head width, Larval body length and Larval body width. After measuring pit characteristics, larval size were measured on the spot. Non-resident pits were also taken note off. The larvae of non -resident pits either leave the pit because of food scarcity or by adverse physical conditions. The data's were analysed by standard statistical methods and software's.

The instar was determined by using the highly correlated parameters. From the correlation study the instar of the larvae inhabiting the pit can be predicted using the pit parameters. And also, the trailing behaviour of larvae was observed under laboratory condition. From this observation a short note was made. For this purpose, a single larva was placed on a single tray, and the trailing initiation and progress was analyzed prior to pit making. The dimension of the tray was $23 \mathrm{~cm} \times 23 \mathrm{~cm}$ and soil depth was fixed to 3.2 $\mathrm{cm}$ in each experiment. 
International Journal of Science and Research (IJSR)

ISSN (Online): 2319-7064

Index Copernicus Value (2013): 6.14 | Impact Factor (2014): 5.611

\section{Results}

\begin{tabular}{|c|c|c|c|c|c|c|}
\hline \multicolumn{7}{|c|}{ Correlation } \\
\hline & $P D E$ & $P D I$ & $L H L$ & $L H W$ & $L B L$ & $L B W$ \\
\hline PDE & 1 & & & & & \\
\hline PDI & -0.08251 & 1 & & & & \\
\hline LHL & -0.22056 & 0.216193 & 1 & & & \\
\hline LHW & -0.16066 & 0.355969 & 0.681227 & 1 & & \\
\hline LBL & 0.021572 & 0.397212 & 0.371056 & 0.596104 & 1 & \\
\hline LBW & -0.1565 & 0.587012 & 0.58401 & 0.513509 & 0.518773 & 1 \\
\hline
\end{tabular}

Fig. 1 Correlation results showing relationships between the different parameters of pit size and larval size.

PDE- Pit depth PDI- Pit diameter LHL-Larval head length LHW-Larval head width LBL- Larval body length LBWLarval body width.

From the correlation results it was noted that, there is a negative correlation between larval head length and pit depth. That is, the pit depth increased with the decrease of larval head length. So smaller the head length of antlion larvae, bigger the depth of pits. Also, there is a high positive correlation between larval body width and pit diameter. That is the pit diameter increases with the increase in larval body width. There is no relationship between the larval body length and pit depth. The larval body width may help the larvae to make the pits with larger diameter. From this study, it is clear that other parameters of pit do not have any relationship with the inside dwelling larvae. Also there is a high positive correlation between pit depth and diameter. The pit depth increases with the increase in diameter.

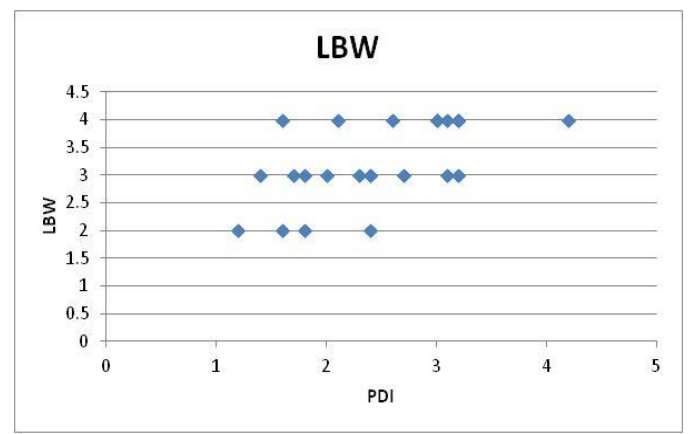

(a)

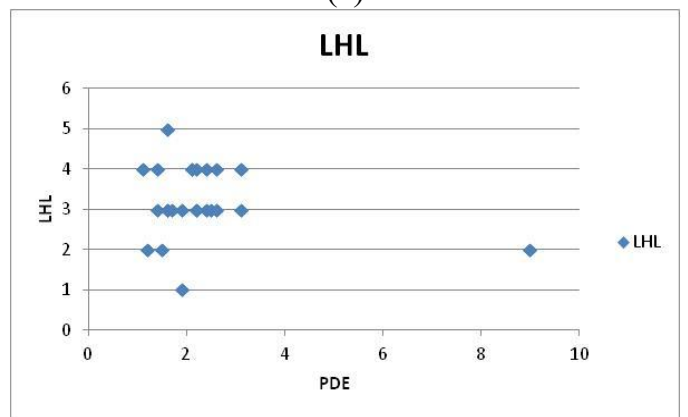

(b)

Figure 2: (a) Positive relation between larval body width and pit diameter. (b) Negative relation between larval head length and pit depth.

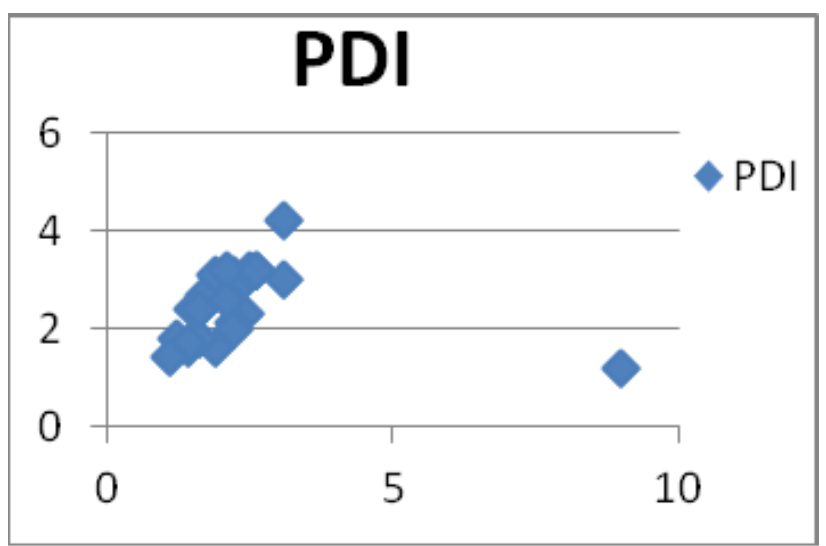

Figure 3: Graph showing the positive correlation between pit depth and diameter.

The high positive correlation results of larval body width and pit diameter were used for the instar determination study. Here the pit diameter is splitted into three classes according to their values, that are 1.2-2.2, 2.2-3.2, 3.2-4.2, from these classes the average larval body width in each diameter was calculated by taking its average. The result is furnished below.

Table 1: The expected larval body width as per diameter of pits

\begin{tabular}{|c|c|c|}
\hline PDI & LBW (number) & Mean LBW \\
\hline $1.2-2.2$ & 18 & 2.88 \\
\hline $2.2-3.2$ & 20 & 3.35 \\
\hline $3.2-4.2$ & 10 & 3.80 \\
\hline
\end{tabular}

From this table, we can predict the larval size of pitdwelling larvae by measuring its diameter. It is known that antlions have three larval instars during its life cycle. Here the average size of each larvae in each instar is determined. The average body width of first instar larvae is approximately $2.88 \mathrm{~mm}$ seen in the pit with diameter ranging from $1.2-2.2 \mathrm{~cm}$. The average body width of second and third intar larvae is approximately 3.35 and $3.80 \mathrm{~mm}$ respectively which is seen in pit diameter ranging from 2.23.2 and $3.2-4.2 \mathrm{~cm}$. Simply it can be determined that, the Pits with diameters ranging from 1.2-2.2, 2.2-3.2, 3.2-4.2 cm have the larvae with body width $2.9,3.4,3.8 \mathrm{~mm}$ respectively. 


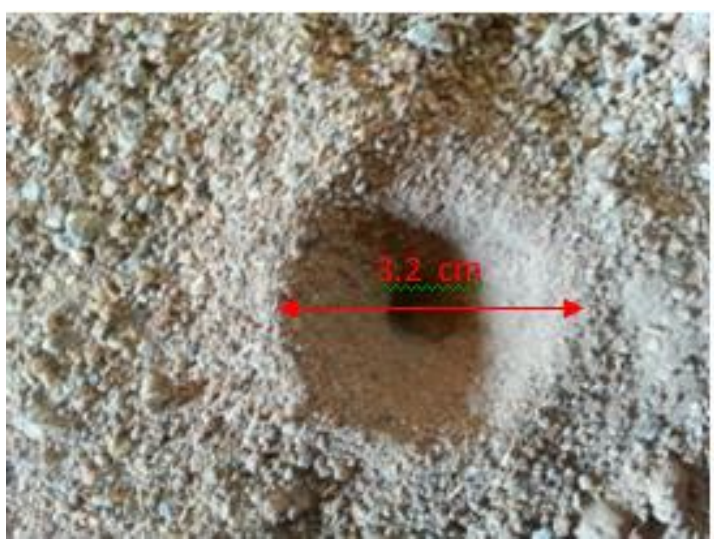

Figure 4: Showing the correlation between pit diameter and larval body width.

The trailing behaviour of antlion larvae was observed in laboratory condition. Single larvae placed in each tray were observed. From this study some predictions are made

(1) The trailing started between $3 \mathrm{sec}$ to 50 minutes from the introduction of larvae to the soil.

Most of the time it started trailing within 3 seconds.

(2) In all the experiments the larvae first moved from the centre portion of the tray to the periphery.

(3) The larvae make its pits only after the calculation of the boundary of the habitat or environment by moving on to the periphery of the tray.

(4) All the time the trailing started from the centre to the north of the tray, and moved closer back to the centre.

(5) After fixing the correct location for its pit- building, the backward rotation starts with the flipping of soil.
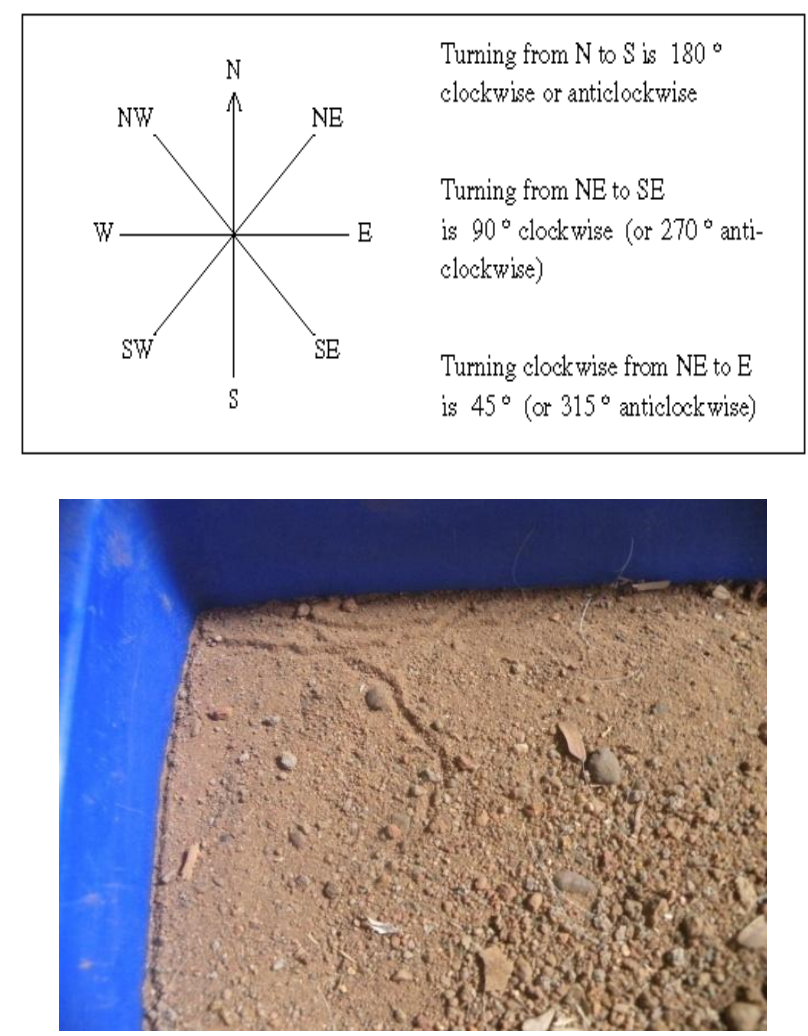

(a)

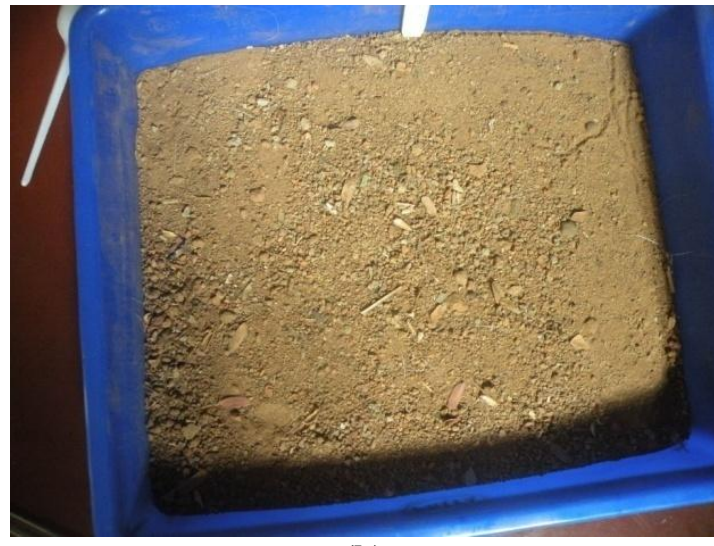

(b)

Figure 5: showing northward movement (a) and periphery movement (b).

\section{Discussion}

Antlions make their pits in shady places which are darker and cooler than areas exposed to sun (Klein 1982). Mostly, partially built buildings, abandoned houses, sandy areas are their favourite place to make pits. So many studies were conducted regarding pit building, foraging strategies etc., of which the pit diameter and pit depth are significant because it ensures the success of prey capture (Heinrich \& Heinrich 1984, Scharf \& Ovadia 2006). But the relationship between the larvae and its pits is somewhat new. The result shows a high positive correlation between the larval body width and pit diameter. It is known that antlions make their pit by the backward movement through soil and by flipping soil with the mandibles. So, the larvae having large body width cause the increase in diameter of pit while moving. It may help to stabilize the sand or soil from sliding down.

Some studies regarding pit size point out that the pit size will increase while short term starvation and it will decrease on long term starvation (Heinrich \& Heinrich, 1984). But here, the study was emphasised on the larval size and pit size aspects. Many studies point out that there is a relationship between pit diameter and larval size without specifying whether it is body width, head length etc. But this study emphasises these aspects and finds an amazing relationship between pit and larval size parameters. Here there is a negative correlation between larval head length and pit depth, and also, there is a high positive correlation between larval body width and pit diameter. If we just measure the 


\section{International Journal of Science and Research (IJSR) \\ ISSN (Online): 2319-7064}

Index Copernicus Value (2013): 6.14 | Impact Factor (2014): 5.611

diameter of the pit, we can predict the body width of the larvae without seeing it.

Trailing behaviour is an important aspect regarding antlion and is only seen in antlion larvae. Experimentally it is proved that when a larvae is placed in the centre of the tray filled with sand, firstly the larvae moves to the edge of the tray in response to microclimatological factors (Heinrich and Margaret 1984). It is also true that the larvae was moved to the edge of the tray immediately after putting in to the tray, and interestingly it is seen that the larvae every time moves towards the north and comes back to the centre position and then it starts to build the pit. But the reason for northward movement is not known. Studies revealed that the amount of space used by an organism can be energetically determined (Swenson et al. 2007). There are so many pits which are non resident pits. The studies reveal the fact that almost $38 \%$ of the pits did not contain antlions (Boake et al.1984). As per this study, the percentage of non- resident pits is found to be $20 \%$, may be due to unknown reasons.

\section{Acknowledgements}

We thank our Principal Dr. Jenson. P. O, St. Thomas' College, Thrissur for providing infrastructural facility for doing this research. And also Ms. Sajana O. K, Guest lecturer, Dept. Of Statistics, St. Thomas (Autonomous) College, Thrissur for the assistance rendered for the statistical analysis of data.

\section{References}

[1] AE. Arnett , NJ. Gotelli, "Bergmann's rule in the antlion Myrmeleon immaculatus DeGeer (Neuroptera: Myrmeleontidae): geographic variation in body size and heterozygosity", Journal of Biogeography ,26, pp. 275$283,1999$.

[2] BG. Klein, "Pit construction by antlion larvae: Influences of soil illumination and soil temperature". Newyork entomological society 90, pp. 26-30, 1982.

[3] B. Heinrich, MJE. Heinrich, "The pit trapping foraging strategy of the antlion, Myrmeleon immaculatus DeGeer (Neuroptera: Myrmeleontidae)". Behaviour ecology and socio-biology 14, pp. 151-160, 1984.

[4] CRE. Boake, D. Andow , PK. Visscher "Spacing of antlions and their pits". American Midland Naturalist 111, pp. 192-194, 1984.

[5] D. Griffiths ," The feeding biology of antlion larvae; prey capture, handling and utilization". Animal ecology 49, pp. 99-125, 1980

[6] D. Griffith," The feeding biology of antlion larvae: growthand survival in Morter obscures “.Oikos 34, pp. 364-370, 1980.

[7] DS. Simberloff, L. King, P. Dillon ,S. Lowrie, D. Lorence, E. Schilling "Holesin the doughnut theory: the dispersion of antlions". Brenesia14-15, pp. 13-46, 1978.

[8] Scharf, O. Ovadia " Factors influencing site abandonment and site selection in a sit and wait predator: a review of pit building antlion larvae". Journal of insect behaviour 19, pp. 197-218, 2006.

[9] NG. Swenson, DL. Mahler, M. Ferro , A. Rictchie , "The energetic determination, spatial dispersion and density dependence of Myrmeleon antlion pits in Las Cruces, Costa Rica”. Biotropica 39, pp. 774- 777 , 2007.

[10] PKL. Prado, LC. Bede, L. Faria, "Asymmetric competition in a natural population of antlion Larvae". OIKOS 68, pp. 525-530, 1993.

[11]RL. Kitching, "Some biological and physical determinants of pit size in larvae of Myrmeleon pictifrons gerstaecker (Neuroptera: Myrmeleontidae)". Journal of Australian Entomologic society 23, pp. 179$184,1984$.

[12] SH. Liang, WY. Lin, YC. Lin, YC. Chen, BS. Sheih," Variations in the pit size of Cueta sauteri (Neuroptera: Myrmeleontidae) larvae in response to past pit building experience and food Limitation". Zoological studies 49, pp. 102-107, 2010. 